Review

\title{
Hypnosis for Clinical Pain Management: A Scoping Review of Systematic Reviews
}

Anupa Pathak ${ }^{1, *}$, Saurab Sharma ${ }^{2,3}$, Mark P. Jensen ${ }^{4}$

1. Centre for Musculoskeletal Outcomes Research (CMOR), Dunedin School of Medicine, University of Otago, Dunedin, New Zealand; E-Mail: pathak.anupa1@gmail.com

2. Centre for Musculoskeletal Outcomes Research (CMOR), Dunedin School of Medicine, University of Otago, Dunedin, New Zealand; E-Mail: saurabsharma1@gmail.com

3. Department of Physiotherapy, Kathmandu University School of Medical Sciences, Dhulikhel, Kavre, Nepal

4. Department of Rehabilitation Medicine, University of Washington, 325 Ninth Avenue, Seattle, WA, USA; E-Mail: mjensen@uw.edu

* Correspondence: Anupa Pathak; E-Mail: pathak.anupa1@gmail.com

Academic Editor: Giuseppe De Benedittis

Special Issue: Hypnosis: From Neural Mechanisms to Clinical Practice

OBM Integrative and Complementary Medicine

2020, volume 5 , issue 1

doi:10.21926/obm.icm.2001005
Received: December 30, 2019

Accepted: January 22, 2020

Published: February 5, 2020

\begin{abstract}
There is a growing body of research evaluating the effects of hypnosis for the management of clinical pain. A summary of the recent systematic review would help understand the quality of evidence regarding the efficacy of hypnosis, and provide directions for future research. We conducted a scoping review of systematic reviews and meta-analyses on the efficacy of hypnosis for management of clinical pain conditions published after 2013. We searched four databases and two reviewers independently screened studies. We extracted information regarding efficacy of hypnosis, quality of trials reviewed, and author's conclusions from the included reviews. We included 13 systematic reviews or meta-analyses that synthesized results from 77 unique clinical trials published from 1841 to 2017 . There
\end{abstract}

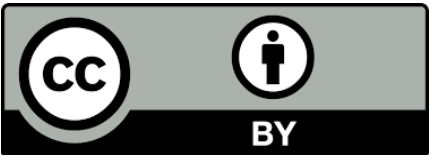

(C) 2020 by the author. This is an open access article distributed under the conditions of the Creative Commons by Attribution License, which permits unrestricted use, distribution, and reproduction in any medium or format, provided the original work is correctly cited. 
was a large degree of heterogeneity in the hypnosis interventions evaluated in the trials. Overall, the authors concluded that there was low-quality evidence for beneficial effects of hypnosis in the management of procedural pain, headache and pain associated with breast cancer care. All 13 reviews concluded that higher-quality trials were needed. Hypnosis may be an effective treatment for a variety of clinical pain conditions. However, the efficacy of hypnotic treatment for clinical pain is yet to be verified in high-quality trials. Researchers should follow recommended guidelines, checklists, and tools to avoid the common methodological shortcomings of previously published trials.

\section{Keywords}

Hypnosis; hypnotic analgesia; review; pain management

\section{Introduction}

Both acute and chronic pain remain significant problems worldwide and contribute to suffering and disability. Pain and anxiety are common with many invasive medical procedures [1], and greater exposure to procedural and surgery-related pain can lead to negative long-term outcomes $[2,3]$. Chronic pain is also common, with a prevalence rate of $37 \%$ to $41 \%$ [4]. Given the problems associated with biomedical approaches to pain treatment including limited efficacy and adverse events [5-7], and given the increasing understanding that pain is the end result of multiple biological, psychologic, and social factors, there has been a growing interest in the use of psychosocial interventions for pain treatment [8-10].

One psychological treatment that has the potential to benefit many individuals with both acute and chronic pain is hypnosis. Hypnosis has been defined as "A state of consciousness involving focused attention and reduced peripheral awareness characterized by an enhanced capacity for response to suggestion." (page 6, [11]). It usually involves several specific components [12-14]. First is a "hypnotic induction" during which the patient or hypnotic subject is invited to focus his or her awareness on a specific object or experience, such as the therapist's voice, a spot on a wall, or their own breathing. This is sometimes, but not always, followed by suggestions for "deepening" the hypnotic experience. The deepening suggestions, when included as a part of the hypnosis intervention, may involve inviting the subject to experience themselves as riding in an elevator or on an escalator that takes them "down" to "deeper and deeper levels of comfort and awareness." The induction and deepening are then usually followed by suggestions that target the symptom or presenting problem. These usually invite the subject or patient to experience changes in their emotions (e.g., to experience a sense of calm or joy), sensations (e.g., to experience physical comfort), or behaviors (e.g., to engage in behaviors associated improved health, such as regular exercise). The clinical suggestions can, and often do, also include "post-hypnotic" suggestions that the changes in emotions, sensations, or behaviour will last beyond the session. For example, they might include suggestions for experiencing comfort and relaxation during an upcoming planned medical procedure. Or they might include suggestions for experiencing greater comfort (i.e., less pain) throughout the day outside of the hypnotic sessions. The clinicians might also make an audio 
recording of the session and offer the subject or patient to listen to the recording between treatment sessions (e.g., once or twice every day).

A large and growing number of clinical trials have been conducted to evaluate the efficacy of hypnosis for pain management. Moreover, reviews of these trials - including both systematic reviews and meta-analyses (which are considered as providing the highest level of evidence) have also been published [15-18]. A useful next step would be to perform a review of these reviews in order to summarize the current state of the evidence regarding the overall efficacy of hypnosis for clinical pain, which in turn could potentially inform future research and the clinical application of hypnosis and hypnotic procedures. A good place to start for such a review is a scoping review. Scoping reviews are an ideal form of review to provide an initial summary of the types of available evidence, understand knowledge gaps, and clarify concepts that would all be useful as a precursor to a systematic review [19].

Given these issues, the primary aim of this scoping review of reviews was to better understand: (1) the type of evidence available, (2) the overall quality of that evidence as reported in the reviews, (3) identify critical knowledge gaps with respect to research in this area, and (4) and provide recommendations for future clinical trials and reviews of those trials regarding the effects of hypnosis on clinical pain.

\section{Materials and Methods}

\subsection{Overview}

We conducted a scoping review of the literature to identify reviews synthesizing trials on the effectiveness of hypnosis for pain management. Although the study protocol was determined a priori, the review was not pre-registered online. This scoping review was conducted in line with Joanna Brigg's Institute's guidelines for scoping reviews [20] and reported based on the PRISMA Extension for scoping reviews [21]. An initial search of four databases for recent reviews of research evaluating the efficacy of hypnotic treatments for pain was conducted on August 21, 2019. A second (final) search was conducted on December 31, 2019, to identify any reviews that met the review inclusion criteria that were published after August 21, 2019. Here we elected to limit the published reviews to include only those published recently (since January 1, 2014).

\subsection{Inclusion Criteria}

In this review of reviews, we included systematic reviews or meta-analyses that focused on evaluating the efficacy of hypnosis for any clinical pain condition (i.e., procedural, acute or chronic pain) if they were written in English (based on the author's language proficiencies) and were published on January 1, 2014, or later. Only studies published on or after January 1, 2014, were included in order to ensure that the most recent evidence are captured. We included systematic reviews and/or meta-analyses of both randomized controlled trials (RCTs) and non-randomized studies of effects hypnotic interventions primarily on pain. To be included, the reviews needed to have reported findings on at least one of the following pain outcomes: pain intensity, pain interference, pain affect, use of pain medication, or satisfaction with pain relief. 


\subsection{Exclusion Criteria}

We excluded: (1) reviews that were published on or before December 31, 2013; (2) reviews of the effects of hypnosis on experimental pain; and (3) overviews or umbrella reviews.

\subsection{Procedures}

Search Strategy: We conducted a systematic search of four databases PsycINFO (via Ovid), PubMed, Cochrane Review database and SCOPUS using a combination of "hypnosis" (or "hypnot*") AND "pain" AND "reviews or meta-analysis". The initial search was performed in August 21, 2019 and an updated search was conducted on December 31, 2019, to capture any reviews published between August and December 2019. For example, the search term used in PubMed was (((Hypnosis [Title]) OR (Hypnot*[Title])) AND (Pain [Title/Abstract])) AND (review [Title/Abstract] OR meta-analysis [Title/Abstract]). The search filter was then used to limit studies published on or after January 1, 2014. The search terms and filters were adapted as appropriate for the different databases. We also screened the reference list of included reviews to identify any additional relevant reviews that might not have been captured by the database searches.

Data extraction and analysis: The lead author independently performed all data charting. The review authors created and approved a data extraction form based on the Joanna Briggs Institute recommendations for reviews [20, 22]. The data extraction form included: author names, publication date, description of the populations studied in the trials that were reviewed, number of studies reviewed, sample size (total number of subjects in all of the trials reviewed combined, as well as the median and range of the number of subjects in the individual trials), quality of the included trials as reported by the review author, the number of studies included in the metaanalysis (for meta-analyses), the key findings of the reviews including information on study heterogeneity, and the authors' primary conclusions. If there were missing data, we recorded it as such and did not consult the authors or the primary studies or review authors, since the aim of this paper is to provide an overview of the reviews and not of primary sources or clinical trials. We then performed a narrative synthesis of the reviews to describe types of hypnosis used, types of comparator groups, quality of trials within the reviews, and effectiveness of hypnosis for pain management. As this was a scoping review of literature, we did not assess the quality of included reviews [19].

\section{Results}

\subsection{Scope of Current Literature}

\subsubsection{Search Results}

We retrieved a total of 70 papers from the four databases on August 21, 2019, and then removed 24 duplicates. AP and MJ independently screened the remaining 47 articles - only 18 of these were systematic reviews or meta-analyses. Five of these were excluded from the current scoping review of reviews because they were not written in English $(n=2)$ [23-25] or did not primarily examine the effects of hypnosis on one of the pain outcomes (e.g., pain intensity, analgesic medication use, etc.; $n=2)[26,27]$. We did not identify any new articles with our second search performed on December 31, 2019. 


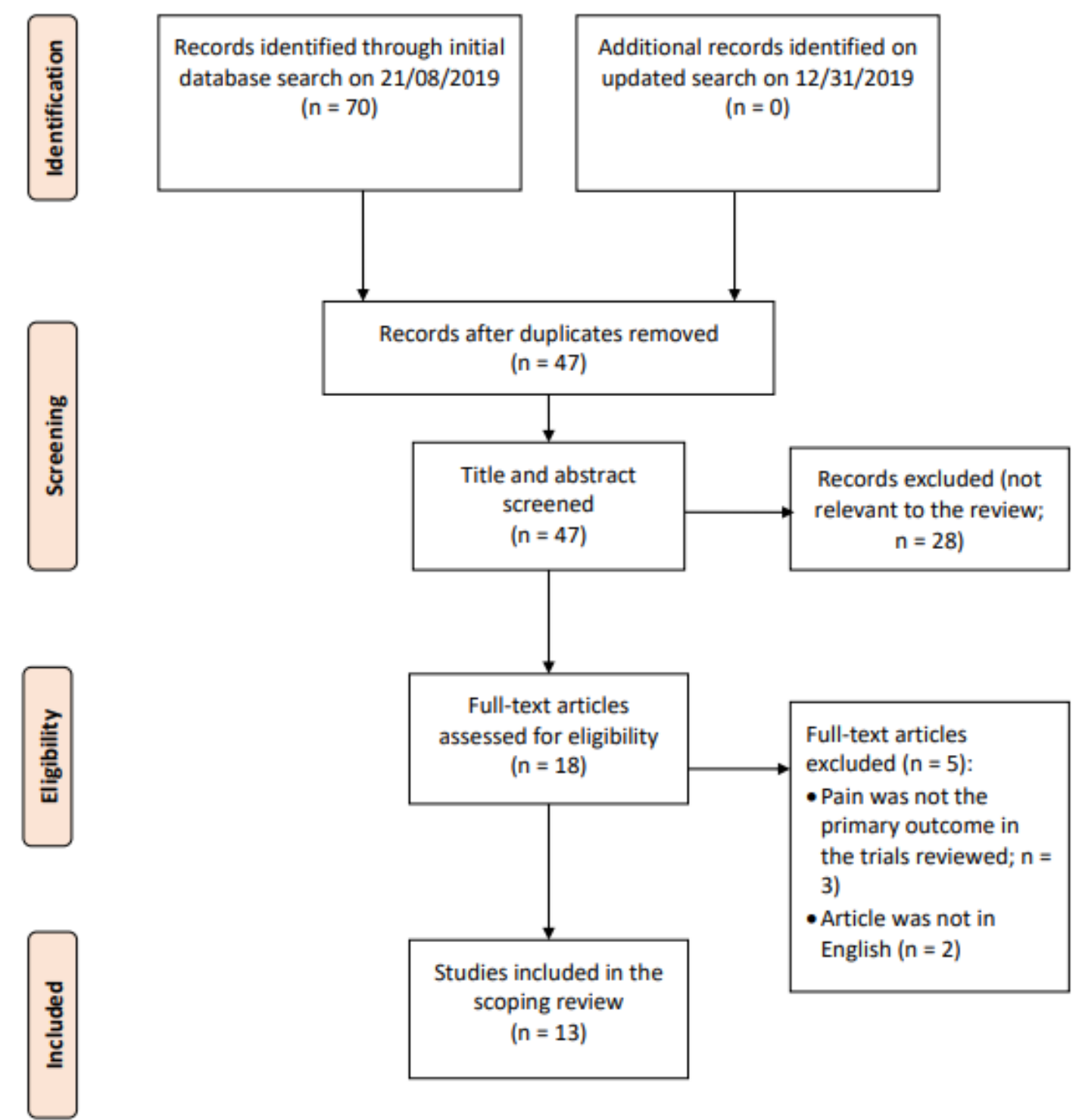

Figure 1 PRISMA Flow diagram.

Thus, we included a total of 13 systematic reviews or meta-analyses that synthesized results from 99 RCTs or non-randomized clinical trials published from 1841 to 2017 that evaluated the effects of hypnosis on pain [15-18, 28-36]. There were overlapping trials between reviews: overall, there were 77 unique trials that included data from more than 6,882 participants (one review did not report sample sizes [33]). A large proportion of these RCTs were published before January $2009(70 \%, n=69)$ and 38\% ( $n=37)$ were published before January 2000.

Five of the reviews summarized in this paper reviewed the effects of hypnosis on procedural pain $[18,28,29,34,35]$, four reviewed studies examining the effects of hypnosis on chronic pain $[16,32,33,36]$, and four reviewed trials that examined the effects of hypnosis on other pain conditions $[15,17,30,31]$. However, the authors of one of the reviews that sought to evaluate the effects of hypnosis on end-of-life cancer pain were unable to find any trials to review that met their inclusion criteria [31]. 


\subsubsection{Hypnosis Interventions and Comparators}

There was a great deal of missing information regarding the details of the hypnosis treatments evaluated in the clinical trials reviewed, as well as the comparators used. However, based on the limited information that was provided by the review authors, it was clear that there was a large variation in how hypnosis treatment was provided in the trials reviewed, as well as the comparators used in the 72 trials (see Supplementary Table S1).

Based on the information provided in the thirteen reviews, thirty-eight trials examined the effects of self-hypnosis using audio recordings, most often (but not always) after one or more face-to-face hypnosis sessions $[15-17,28,29,33,35,36]$. Five unique trials included in three reviews used audio recordings to teach hypnosis without any face-to-face sessions [17, 18, 35]. Although most trials provided hypnosis treatment to individual patients, the reviewers also reported on some trials that used group therapy for teaching hypnosis [15, 29, 36]. Seven trials included in two reviews used hypnosis combined with visual or thermal imagery [28, 33]. Many of the trials reported on the findings from studies that used hypnosis to provide suggestions for analgesia, although others included non-analgesic hypnotic suggestions [28, 33].

As noted previously, the reviews provided minimal information regarding the details of the hypnosis interventions studied in the clinical trials that were reviewed, perhaps in part because the original trials provided minimal or inadequate information. The review authors used terms such as "live hypnosis"[17, 18, 29], "direct hypnosis" or "indirect hypnosis" [33], "tailored hypnosis" $[15,32]$, and "standard hypnosis"[15, 29] to describe the hypnosis treatments being studied. The most common hypnotic technique studied in the trials reviewed in the 13 reviews was an adapted version of Rapid Induction Analgesia (also called Barber's technique; [18, 34, 37]). Other techniques included what the authors referred to as "Ericksonian" hypnosis [18, 28, 32], Jacobson's hypnosis [16], Gardner's Technique [18, 28], Enquivist's technique, Elmal's technique, and Olness's technique [18].

There were also large differences in the dose (e.g., number and length of sessions) of hypnosis and who provided the hypnotic interventions. Three reviews did not provide any information regarding the dose used in the trials reviewed [28, 30, 33], and only seven reviewers provided some information regarding who provided the hypnosis treatment, including the level of expertise of the clinicians [15, 28-30, 34-36]. Only one review reported on the training and experience of the treatment deliverer [35]. This review noted whether or not the treatment providers were trained. The frequency of hypnosis sessions ranged from just one session (most often in studies evaluating the effects of hypnosis for medical procedure-related pain; [17, 18, 34-36] to as many as fourteen sessions for treatment of chronic conditions such as fibromyalgia [32] and forty-eight sessions for ongoing breast cancer care [29]. A similar variation was also seen in the duration of individual sessions, which varied from 10 minutes [18, 35] to 2 hours [32]. Hypnosis interventions were delivered in the trials by psychologists, hypnotherapists, nurses, medical students, physicians, research assistants and psychotherapists. When hypnosis treatment was offered to treat pain associated with medical procedures, some trials provided hypnosis treatment before the painful procedure, while others provided hypnosis during the procedure [18, 28, 29, 34, 35].

Hypnosis treatment was compared against both active control conditions and standard care in the trials reviewed. Twenty-five trials compared hypnosis to usual care [15-17, 28, 35], nine to relaxation [15-17, 33, 36], six to attention control conditions [28-30], and five each to autogenic 
training $[16,32,33]$ and to biofeedback [16, 17, 33]. Eleven trials compared hypnosis to no treatment or waiting list [15, 16, 30,36]. Flynn [33] reported the use of "placebo" in four trials. However, these authors did not describe what the placebo intervention referred to (i.e., whether it was a medication placebo or some other placebo or sham intervention). Trials also studied the effects of hypnosis when combined with other active treatments, such as CBT (versus CBT alone; [32]) or lorazepam (versus lorazepam only) [34].

\subsubsection{Quality of Evidence}

All included reviews, except the one that was unable to identify any trials to include in the review [31] and a recent review by Eason [17], assessed the quality of included trials using a validated tool. Six studies used the Cochrane Risk of Bias tool [15, 28-30, 32, 34], and one each used the PEDro Scale [33], critical appraisal instrument from the Joanna Briggs Institute MetaAnalysis of Statistics Assessment and Review Instrument (JBI-MAStARI) [35] and Jadad Score [18], Downs and Black's Quality Index [36] and Yates scale [16]. The authors that assessed study quality reported that all or almost all of the trials included in their reviews were of low or moderate quality. Only two reviews rated some clinical trials as being of high quality - the studies reported by Madden and colleagues and Cramer and colleagues [15, 29]. Overall, the clinical trials reviewed in these reviews were viewed as having inadequate reporting of randomization procedures, allocation concealment and blinding of outcome assessor [15, 16, 18, 28-30, 32-36]. The review authors also indicated that they had difficulties with assessing selective outcome reporting due to a lack of trial registration [15, 16, 28, 29, 32-34]. Adachi and colleagues [16] noted the methodological quality of clinical hypnotic intervention studies had remained poor even for the most recently published studies, although there has been a trend for trials to use larger sample sizes. There were also concerns expressed by the reviewers about the potential lack of experience in delivering hypnosis in the study clinicians, potential problems with patient adherence to procedures, and inadequate reporting of missing data $[15,18,30]$.

\subsection{Current Evidence Regarding the Efficacy of Hypnosis}

\subsubsection{Efficacy of Hypnosis for Procedural Pain}

Five reviews including a total of 3172 participants synthesized the effects of hypnosis on procedural pain (see Table 1) [18, 28, 29, 34, 35]. Noergaard and colleagues [35] conducted a systematic review of nine randomized controlled trials and one quasi-experimental study that assessed the effectiveness of hypnosis in adults undergoing minimally invasive medical procedures. The authors were unable to conduct a meta-analysis on effects on pain intensity and use of medication due to large heterogeneity in the outcomes studied. In eight of the studies, there were no significant differences between hypnosis and the control condition in patient-rated pain intensity. However, based on five trials that reported on use of pain medication, the authors of the review concluded that there was a decrease in pain medication consumption by $21 \%$ to $86 \%$ in the hypnosis groups compared to usual care alone. 
Table 1 Summary of included reviews on hypnosis and pain.

\begin{tabular}{|c|c|c|c|c|c|}
\hline Author, Year & Clinical population & $\begin{array}{l}\text { No. Of } \\
\text { studies }\end{array}$ & $\begin{array}{l}\text { Total sample size } \\
\text { (Range, Median) }\end{array}$ & $\begin{array}{l}\text { Meta-analysis } \\
\text { (no. of studies) }\end{array}$ & Key findings \\
\hline Noergaard, 2019 [35] & $\begin{array}{l}\text { Adults undergoing } \\
\text { minimally invasive }\end{array}$ & 10 & $\begin{array}{l}1364 \text { ( } 26 \text { to } 350, \\
105)\end{array}$ & $\begin{array}{l}\text { Yes, but not for } \\
\text { outcomes procedures } \\
\text { of interest }\end{array}$ & $\begin{array}{l}\text { - Hypnosis = Usual care [pain intensity] }(n=8) \\
\text { - Less pain medicine consumption in hypnosis } \\
\text { group }(n=5)\end{array}$ \\
\hline Eason et al., 2018 [17] & $\begin{array}{l}\text { Adults with mixed } \\
\text { clinical pain } \\
\text { conditions }\end{array}$ & 11 & $\begin{array}{l}2656 \text { (15 to } 1,222, \\
60)\end{array}$ & $\begin{array}{l}\text { Yes, but not pain- } \\
\text { specific }\end{array}$ & $\begin{array}{l}\text { - Self-hypnosis > Other active controls* }(n=6) \\
\text { - Self-hypnosis > Standard care }(n=2) \\
\text { - Self-hypnosis not useful for labor pain }(n=3)\end{array}$ \\
\hline Flynn, 2018 [33] & Adults with migraine & 8 & Not Reported & No & $\begin{array}{l}\text { - Hypnosis }>\text { Autogenic training }(n=2) \\
\text { - Hypnosis }>\text { Biofeedback }(n=1) \\
\text { - Hypnosis = Non-hypnotic imagery }(n=1)\end{array}$ \\
\hline Provencal et al., 2018 [34] & $\begin{array}{l}\text { Burn patients } \\
\text { receiving wound care }\end{array}$ & 6 & $234(26$ to 61,31$)$ & Yes (5) & $\begin{array}{l}\text { - Hypnosis }>\text { Attention control and medication } \\
\text { conditions }[(\mathrm{MD}=-8.90,(95 \% \mathrm{Cl}-16.28 \text { to } \\
-1.52)]^{* *}\end{array}$ \\
\hline $\begin{array}{l}\text { Montgomery et al., } 2017 \\
\text { [31] }\end{array}$ & Cancer patients & 0 & - & - & - No studies met inclusion criteria \\
\hline Zech et al., 2017 [32] & $\begin{array}{l}\text { Adults with } \\
\text { fibromyalgia }\end{array}$ & 5 & $229(32$ to 63,40$)$ & Yes (9) & $\begin{array}{l}\text { - Hypnosis = CBT }(n=2) \\
\text { - Hypnosis }>\text { Physiotherapy and no treatment } \\
\text { at } 3 \text { months [NNT for } 30 \% \text { decrease in pain }=5 \\
(95 \% \mathrm{Cl}, 3 \text { to } 50)]\end{array}$ \\
\hline Madden et al., 2016 [15] & Women in labor & 9 & $\begin{array}{l}2954 \text { (38 to } 1,222, \\
65)\end{array}$ & Yes (9) & $\begin{array}{l}\text { - Hypnosis }>\text { Usual care and supportive therapy } \\
\text { [RR to use pain relief }=0.73(95 \% \mathrm{Cl} 0.57 \text { to } \\
0.94)](n=8)\end{array}$ \\
\hline
\end{tabular}




\begin{tabular}{|c|c|c|c|c|c|}
\hline Cramer et al., 2015 [29] & $\begin{array}{l}\text { Women diagnosed } \\
\text { with or suspected of } \\
\text { having breast cancer }\end{array}$ & 5 & $\begin{array}{l}671 \text { (20 to } 240, \\
125)\end{array}$ & No & $\begin{array}{l}\text { - Pre-operative hypnosis > Attention }(n=1) \\
\text { - Pre-operative hypnosis > Usual care }(n=2) \\
\text { - Hypnosis + exercise > Self-education }(n=1) \\
\text { - Hypnosis + support group > Usual care and } \\
\text { support group only }(n=1)\end{array}$ \\
\hline Zhang et al., 2015 [30] & $\begin{array}{l}\text { Adults with temporo- } \\
\text { mandibular disorders }\end{array}$ & 2 & $64(25-39,32)$ & Yes (2) & $\begin{array}{l}\text { - Hypnosis > No treatment and attention } \\
\text { control }[\mathrm{MD}=-28.33 \text {; }(95 \% \mathrm{Cl}:-44.67 \text { to - } \\
11.99)]^{* *}\end{array}$ \\
\hline Adachi et al., 2014 [16] & $\begin{array}{l}\text { Adults with chronic } \\
\text { pain }\end{array}$ & 12 & $\begin{array}{l}669 \text { ( } 22 \text { to } 157, \\
42)\end{array}$ & Yes (12) & $\begin{array}{l}\text { - Hypnosis > Standard care } \\
\text { [g =.60, }(95 \% \text { Cl } 0.03 \text { to } 1.17)](n=4) \\
\text { - Hypnosis = Other psychological } \\
\text { interventionst }(n=11)\end{array}$ \\
\hline Birnie et al.,2014 [28] & $\begin{array}{l}\text { Children undergoing } \\
\text { needle punctures }\end{array}$ & 7 & $225(25$ to 60,30$)$ & Yes (5) & $\begin{array}{l}\text { - Hypnosis > Play, CBT, attention control, and } \\
\text { local anesthesia } \\
[\mathrm{SMD}=1.40 \text { ( } 95 \% \mathrm{Cl} 2.32 \text { to } 0.48)]\end{array}$ \\
\hline Bowker et al, 2014 [36] & $\begin{array}{l}\text { Adults with chronic } \\
\text { disability }\end{array}$ & 10 & $365(20$ to 66,34$)$ & Yes (10) & $\begin{array}{l}\text { - Hypnosis > Waiting list [pain intensity] [ES= } \\
0.53(90 \% \mathrm{Cl} 0.28 \text { to } 0.84) \text { ] } \\
\text { - Hypnosis = CBT, other behavior treatment }\end{array}$ \\
\hline Cheseaux et al., 2014 [18] & $\begin{array}{l}\text { Adults and children } \\
\text { undergoing medical } \\
\text { procedures }\end{array}$ & 13 & $\begin{array}{l}678 \text { (20 to } 200, \\
36)\end{array}$ & No & $\begin{array}{l}\text { - Hypnosis > Psychological treatments } ¥(n=4) \\
\text { - Hypnosis > No treatment }(n=3) \\
\text { - Hypnosis = No treatment and other } \\
\text { psychological treatments }(n=5)\end{array}$ \\
\hline
\end{tabular}

*Biofeedback, pain education, attention control, empathy, sedatives.

**Based on a meta-analysis.

†Autogenic Training ( $n=4)$, Relaxation and Visualization $(n=2)$, Progressive muscle relaxation $(n=2), C B T(n=1)$, Supportive Psychotherapy ( $=1)$ and Biofeedback ( $=1)$. ¥ Psychological Interventions used in individual studies not reported by authors.

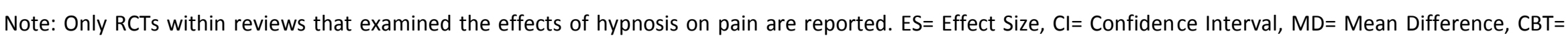
Cognitive Behavior Therapy, NNB= Number needed to Benefit, RR= Risk Ratio, SMD= Standard Mean Difference. 
Provencal and colleagues conducted a systematic review of 6 RCTs published from 1980 to 2017 that compared the use of hypnosis in wound care in adult burn patients [34]. The meta-analysis of 5 trials showed a statistically significant effect of hypnosis on subjective pain intensity among adults undergoing treatment of burns ( $M D=-8.90$ on a $100 \mathrm{~mm}$ scale, $95 \% \mathrm{Cl}-16.28,-1.52$ ) but no effects of hypnosis on the use of analgesic medications. However, due to a small number of studies included in the meta-synthesis, of which four were from the same research group, the authors conclude that results, while promising, need to be interpreted with caution.

Cramer and colleagues [29] also narratively synthesized results of 5 RCTs that examined the effects of hypnosis on pain during breast cancer care (including during a diagnostic biopsy). Of these, three RCTs reported decreases in post-procedural pain compared to standard care, and one of the two RCTs showed significantly lesser pain compared to attention control. The authors recommended that more research is needed to confirm these promising initial findings.

Another review published in 2014 [28] synthesized the findings from nine RCTs examining the effects of hypnosis for decreasing pain and distress during needle procedures in children aged 219 years. Five RCTs including 176 participants showed significant effects of hypnosis on selfreported pain intensity $(S M D=1.40[2.32,0.48], Z=2.97, p<.01,12=85 \%)$ compared to play therapy, attention control, CBT and local anaesthesia. However, based on GRADE ratings, the quality of the evidence from the trials reviewed was deemed to be very low.

Finally, Cheseaux and colleagues [18] reviewed the results of 18 RCTs published before 2012 that evaluated the effects of hypnosis provided before diagnostic or therapeutic medical procedures, such as EMG, surgery, and lumbar punctures among both children and adults. Among 13 trials that reported pain outcomes, eight trials did not find significant effects on pain intensity for hypnosis compared to control conditions, while five reported a significant decrease in pain. However, as with other reviews, the author reported problems with heterogeneity in hypnotic interventions and comparators, as well as a general low methodological quality of the trials they reviewed.

\subsubsection{Efficacy of Hypnosis for Chronic Pain}

We identified four reviews that studied the efficacy of hypnosis in adults with chronic pain [16], disability [36], and fibromyalgia [32] and chronic headache [33]. In the first of these, Adachi and colleagues [16] reviewed results of 12 clinical trials, 6 of which were RCTs and concluded that hypnosis had a moderate effect (Hedges' $\mathrm{g}=.60,95 \% \mathrm{Cl}$ : 0.03-1.17, $\mathrm{p}<.05$ ) on treatment efficacy compared to standard care, but were not significantly more effective than other psychological pain interventions $(\mathrm{g}=.04,95 \% \mathrm{Cl}:-0.22-0.30, \mathrm{~ns})$. However, there was moderate to large heterogeneity for both the results. The authors also recommended that authors need to improve methodological quality in future studies.

A review in 2017 by Zech and colleagues [32] synthesized findings from five RCTs that evaluated the effects of hypnosis on pain in adults with fibromyalgia published between 2010 and 2016 . The trials reported no difference in results between CBT combined with hypnosis compared to CBT alone (Risk Difference 0.08 (95\% $\mathrm{Cl}-0.05,0.21)$ ). In addition, no significant differences were found in the efficacy of either guided imagery or hypnosis when compared to a control condition for a greater than $50 \%$ decrease in pain. However, low-quality evidence with large heterogeneity 
suggested that hypnosis was superior to controls when the outcome was a $30 \%$ decrease in pain intensity (NNTB=5, (95\% Cl 3-50)), suggesting some benefit of hypnosis.

Flynn [33] conducted a systematic review of 8 RCTs evaluating the effects of hypnosis in adults with migraine or chronic headache disorders. Of these, four studies used hypnosis in conjunction with visual imagery and five studies used self-hypnosis techniques. Of the 8 studies included, five out of six studies reported significant decreases in headache activity in participants who received hypnosis compared to those who received other psychological interventions. Four studies found no significant differences between hypnosis treatment when compared to "placebo" (specific placebos used not specified in the review) treatment.

Bowker and colleagues [36] conducted a meta-analysis of studies examining the effectiveness of hypnosis for chronic pain in adults with long-term disabling conditions such as fibromyalgia, osteoarthritis or spinal cord injury. The authors found evidence in favour of hypnosis, with a medium weighted effect size of $0.53(\mathrm{Cl}=0.28-0.84)$ in comparison to no-treatment or educationonly control conditions ( $n=6$ studies). They also found, however, that hypnosis treatment was not significant more effective than cognitive or behavioral pain interventions $(n=6)$. Five studies also showed greater reductions in pain medication use among the participants who received hypnosis at 3 to 6 months, compared to control conditions which included no treatment, relaxation, or physical therapy.

\subsubsection{Efficacy of Hypnosis for Other Pain Conditions}

A recent systematic review by Eason and colleagues [17] reviewed 22 RCTs to assess the clinical uses of self-hypnosis. Only eight of the included RCTs assessed efficacy of self-hypnosis in the management of painful conditions which included chronic pain $(n=3$, one of which also included in [16]), labor pain ( $n=3$, all studies also included in [15]) and procedural pain ( $n=2$, one of which also included in [29]). In all the eight studies reviewed, training in hypnosis followed by self-hypnosis was more effective for reducing pain than control conditions such as biofeedback, structured attention, relaxation, empathy, sedatives, and standard care.

Montgomery and colleagues [31] conducted a systematic search of five databases for RCTs published before November, 2016 that reported data regarding the effects of hypnosis for treating patients with cancer at the end-of-life. Specifically, they looked for outcomes related to pain, fatigue, dyspnoea, appetite loss or sleep disturbance. However, the authors were unable to find any relevant studies and concluded that hypnosis had not yet been rigorously tested in endof-life cancer patients.

A Cochrane review performed in 2016 synthesized findings from 9 RCTs including 2954 patients that evaluated the effects of hypnosis for labor pain [15]. In eight of the studies, hypnosis training was provided during the antenatal period. In one study, the hypnosis intervention was provided during labor. The authors found that women in hypnosis group were less likely to use pharmacological pain relief or analgesia than those in the control groups, (average risk ratio (RR) $0.73,95 \% \mathrm{Cl} 0.57$ to 0.94 , eight studies, 2916 women; very low-quality evidence; random-effects model; substantial statistical heterogeneity), but there was no effect on epidural use. There were no significant differences between the hypnosis group and control groups for satisfaction with pain relief either. 
Finally, Zhang and colleagues [30] reviewed two RCTs that evaluated the efficacy of hypnosis compared to no treatment and attention control in patients with temporomandibular disorders. Based on data from the trials, there was very low-quality evidence that hypnosis was comparable to the control groups for reduction in overall pain (MD= -9.16 mm on $100 \mathrm{~mm}$ scale; $95 \% \mathrm{Cl}$ : 23.47 to $5.14 ; \mathrm{P}=.21$ ) but may have some benefit for reduction in maximal pain (mean difference on $100 \mathrm{~mm}$ scale $=-28.33 ; 95 \% \mathrm{Cl}:-44.67$ to $-11.99 ; \mathrm{P}=.007)$.

\section{Discussion}

The results of this scoping review provide important summary information regarding our current knowledge about the efficacy of hypnosis for clinical pain, as well as the current state of the quality of research in this area. The findings may be useful to clinicians who are considering using hypnosis in their practice, as well as to future researchers. In this section, we discuss the implications of the findings with respect to three specific areas: issues related to the heterogeneity of "hypnosis", recommendations for improving the quality of research, and conclusions regarding treatment efficacy.

\subsection{The Heterogeneity of "Hypnosis"}

The review findings made clear that hypnosis treatments can vary a great deal across a large number of characteristics. Hypnosis treatment can vary with respect "dose" (number and length of face-to-face sessions), frequency of hypnosis treatments, the training and experience of the clinicians providing the treatment, whether or not and the extent to which participants practice hypnosis on their own between sessions (with or without audio recordings to assist them with home practice), and the specific content of the hypnotic inductions and suggestions. Moreover, there is a great deal of heterogeneity with respect to the types of pain conditions examined in this literature [38]. For example, acute pain differs in many important ways from chronic pain, and different chronic pain conditions can differ to a great extent with respect to both type and etiology [39].

Researchers would do well to keep the heterogeneity of hypnosis in mind when designing and conducting hypnosis trials. First, they should carefully consider each component of the hypnosis intervention they plan to test (i.e., dose, treatment frequency, use of experienced clinicians, participant practice, use of audio recordings, and content of the suggestions), perhaps balancing feasibility against the need to maximize efficacy. If the trial authors do not make efforts to maximize efficacy by, for example, providing a minimal number of treatment sessions, encouraging and facilitating between-session practice, and using clinicians with adequate training and experience, it could be difficult to conclude if a null finding is due to a lack of efficacy of hypnosis in general or because of problems with the way that hypnosis treatment was delivered. Also of great importance, researchers should carefully and clearly describe each of these components of the hypnosis treatment tested. This could be done either in the text of the paper that presents the findings, or as supplementary materials (e.g., as a study treatment manual used by the study clinicians and that could be provided to readers who request it). Checklists such as the Template for Intervention Description and Replication (TiDieR) can be useful resources for describing the hypnotic treatments evaluated in the trials [40]. 
By providing this level of detail, future investigators who perform reviews of the literature could then classify each clinical trial with respect to each of these domains, and then evaluate the level of efficacy (e.g., pain reduction) as a function of each factor. They may learn, for example, and that for certain pain conditions, maximum benefit occurs with at least four 60 minute sessions of hypnosis provided by clinicians supervised by very experienced clinicians and that includes suggestions both for pain reduction and for changing the meaning of sensations, but that regular practice at home does not provide any additional benefits. Providing detail regarding the hypnotic treatment being evaluated would also be very important for reviewers to be able to understand when (and for whom) hypnosis has no, minimal or large benefits.

In addition, some research suggests that trait hypnotizability - that is, the tendency of an individual to respond to hypnotic suggestions - might potentially moderate the efficacy of hypnosis for pain management $[41,42,43]$. These moderation effects appear to be more pronounced in laboratory-based settings than studies of patients with clinical pain [44]. However, this issue was rarely addressed in the reviews we summarized in the current study, perhaps in part because researchers tend to not evaluate these effects in clinical trials. We recommend that not only should trials evaluate whenever possible, using one of the several measures of hypnotizability that are available [45], but that future reviews should include a section discussing this issue, specifically.

Another important issue to consider is whether review authors should perform meta-analysis when significant heterogeneity is found in the clinical trials being reviewed. When there is a variety of different treatments (i.e., in this case, different types of hypnosis treatments) and different comparators, it is recommended that the meta-analysis should consider each combination separately [46]. Moreover, meta-analyses should also exclude studies with high risk of bias [46]. Each of the seven meta-analyses included in the current scoping review reported a high level of heterogeneity in the trials reviewed, and some reported additional publication bias. Each of these factors suggests that it may be too early to use a meta-analytic approach to summarize the findings from hypnosis studies. A greater number of high-quality clinical trials that evaluate similar hypnotic approaches and compare them to similar control conditions will be needed before a meta-analyses of this literature will likely be useful.

\subsection{The Low Quality of the Existing Evidence}

Despite the large and growing body of research evidence on the efficacy of hypnosis for clinical pain, all of the reviewers noted that the quality of the clinical trials that have been published is low. Moreover, one review [16] noted that although more recent studies include larger sample sizes, the quality of the evidence has not tended to improve over the years.

In order for the conclusions regarding the efficacy of hypnosis treatments to be more definitive, improving the quality of the research evidence should be given a high priority. Researchers could use any one of a number of research quality rating tools (e.g., [47-49]) as a guide to help ensure that their trials meet the highest possible quality standards. As noted in the results section of this scoping review, the problems noted most often by the reviewers of the hypnosis literature include a lack of detail regarding randomization procedures, a lack of treatment allocation concealment, a lack of blinding of the individual(s) performing the outcomes assessments, and a lack of registration of the trial prior to study enrollment. 
However, although it is possible (and important) to blind the research staff who perform the outcomes assessment to treatment condition, it is extremely challenging to blind treatment providers and study participants to treatment allocation when evaluating the efficacy of behavioral interventions [50,51], including hypnosis. Requiring this level of blinding of clinical trials in this area for a study to be viewed as being of high quality would by definition mean that a high-quality hypnosis clinical trial is next to impossible. Given this, special design features for behavioral clinical trials are needed. These include, for example, the use of multiple (active treatment) comparison conditions, use of "dual-blind" designs in which participants are blind with respect to the treatment condition that is the focus of the trial, and the development of special treatment conditions that control for the non-specific effects of the behavioral intervention, but do not include the components of the treatment thought to have specific effects $[52,53]$.

Moreover, it may make sense to use tools for rating research quality that do not require that the study participant be blind to treatment conditions in order to deem a study as being of high quality. One example of such a tool was introduced in 2005 [54]. This tool focuses on 13 design features that are specific and unique to trials of psychological interventions for pain management. Thus, it emphases the importance of design features important and necessary for such trials (e.g., clinician experience and training, strategies to engage participants in treatment), while placing less emphasis on design features that are of less importance to the design and conduct of studies evaluating the efficacy of psychological interventions (e.g., allocation blinding). It is also more comprehensive than many of the other existing tools. Trialists would do well to consider using this tool as a guide when designing hypnosis trials, and reviewers should consider using this tool (or others that might also be developed specifically for evaluating psychological interventions) when rating the quality of hypnosis clinical trials.

\subsection{The Efficacy of Hypnosis for Pain Management}

The conclusions made by the authors of the 13 reviews we identified regarding the efficacy of hypnosis as a treatment for pain here were inconsistent. Hypnotic treatments were found beneficial in some studies for pain associated with medical procedures such as burn wound care, cancer treatments, and needle puncture. The findings also suggest the possibility that hypnotic treatments can be effective for chronic headache conditions and labor pain. In contrast, other systematic reviews $[16,35,36]$ reported hypnosis was as good as usual care or other psychological interventions for treatment of procedural pain and chronic pain. However, in no case was hypnosis found to be worse than any control condition. In short, the evidence indicates that hypnosis as a treatment for clinical pain remains promising, but not yet proven effective. Strong recommendations for or against the use of medical hypnosis cannot, therefore, be made at this time.

\section{Conclusions}

Hypnosis may be an effective treatment for a large variety of clinical pain conditions, but the efficacy is yet to be verified in high-quality trials. Hypnosis appears to be promising as an intervention compared to no treatment for the pain associated with burn wound management, cancer treatments, needle injections, and a variety of chronic pain conditions. Hypnosis also appears to be as effective as other psychological pain treatments. There is a consensus from the 
systematic reviews that the quality of the trials on efficacy of hypnosis for pain management remains low. Trialists performing research in this field should use recommended guidelines and checklist(s) while planning and reporting their trials. This will allow other researchers to replicate their findings and also allow reviewers to use this information when determining the factors that impact the effects of hypnosis in future studies.

\section{Acknowledgments}

N/A

\section{Author Contributions}

AP, MJ and SS were all involved in designing the protocol of the review. AP and MJ conducted the screening independently, AP conducted the data extraction and all AP, MJ and SS were involved in drafting and editing the manuscript.

\section{Funding}

This study was not funded.

\section{Competing Interests}

One of the team members, Mark P. Jensen, PhD, has published books on hypnosis, and receives royalties for the sales of these books.

\section{Additional Materials (if any)}

The following additional materials are uploaded on the page of this paper. 
1. Table S1 Description of the hypnosis interventions evaluated in the trials reviewed (as reported by trial authors).

\begin{tabular}{|c|c|c|c|c|}
\hline First author, year & Hypnosis Intervention & Comparator(s) & Hypnosis dose & Delivered by \\
\hline \multicolumn{5}{|c|}{ Noergaard et al., 2019 (Review of trials evaluating the efficacy of hypnosis for minimally invasive procedures) [35] } \\
\hline Hilzi, 2015 & "Hypnosis" & Usual care & NR & Physician \\
\hline Norgaard, 2013 & $\begin{array}{l}\text { Guided self-hypnotic relaxation } \\
+ \text { attentive behaviour + usual } \\
\text { care }\end{array}$ & 1) Usual care & NR & Nurse \\
\hline Shenefelt, 2013 & $\begin{array}{l}\text { Hypnotic induction + self- } \\
\text { guided imagery during } \\
\text { procedure + usual care }\end{array}$ & $\begin{array}{l}\text { 1) Usual care } \\
\text { 2) Recorded hypnotic } \\
\text { induction ( group not included } \\
\text { in review) }\end{array}$ & 1 (10 min) session & Physician \\
\hline Slack, 2009 & $\begin{array}{l}\text { Self-hypnosis using audio } \\
\text { recording only }\end{array}$ & $\begin{array}{l}\text { Usual care + audio recording of } \\
\text { patient education booklet }\end{array}$ & 1 (20 min) session & N/A (recordings) \\
\hline Marc, 2008 & Hypnotic relaxation + usual care & Usual care & 1 (20 min) session & Hypno-therapist \\
\hline Lang, 2008 & $\begin{array}{l}\text { Self-hypnotic relaxation with } \\
\text { empathic attentive behavior }+ \\
\text { usual care }\end{array}$ & $\begin{array}{l}\text { 1) Usual care } \\
\text { 2) Empathic attentive } \\
\text { behaviour ( group not included } \\
\text { in review) }\end{array}$ & NR & Research assistant \\
\hline Marc, 2007 & Hypnotic relaxation + usual care & Usual care & 1 (20 min) session & Hypnotist practitioner \\
\hline Lang, 2006 & $\begin{array}{l}\text { Self-hypnotic relaxation with } \\
\text { empathic attentive behaviour }+ \\
\text { usual care }\end{array}$ & $\begin{array}{l}\text { 1) Usual care } \\
\text { 2) Empathic attentive } \\
\text { behaviour ( group not included } \\
\text { in review) }\end{array}$ & $\mathrm{NR}$ & Research assistant \\
\hline Lang, 2000 & $\begin{array}{l}\text { Self-hypnotic relaxation with } \\
\text { empathic attentive behavior }+ \\
\text { usual care }\end{array}$ & $\begin{array}{l}\text { 1) Usual care } \\
\text { 2) Empathic attentive } \\
\text { behaviour ( group not included }\end{array}$ & NR & "Additional person" \\
\hline
\end{tabular}




\begin{tabular}{llll} 
Lang, 1996 & $\begin{array}{l}\text { in review) } \\
\text { Hypnosis using relaxation and } \\
\text { guided imagery + usual care }\end{array}$ & Usual care & NR \\
\hline Eason et al., 2018 (Review of trials evaluating the effects of self-hypnosis)[17] & "Dedicated \\
practitioner"
\end{tabular}

\begin{tabular}{|c|c|c|c|c|}
\hline Downe, 2015 & $\begin{array}{l}\text { Live + self-hypnosis using audio } \\
\text { recordings }\end{array}$ & Usual care & $\begin{array}{l}2 \text { (90-min) sessions, } 3 \text { weeks } \\
\text { apart }\end{array}$ & NR \\
\hline Tan, 2015 & $\begin{array}{l}\text { Live hypnosis with or without } \\
\text { self-hypnosis + self-practice }\end{array}$ & Biofeedback & $\begin{array}{l}8 \text { sessions (time NR) w/ or } \\
\text { w/o practice or } 2 \text { sessions }\end{array}$ & NR \\
\hline Werner, 2013 & $\begin{array}{l}\text { Self-hypnosis using only audio } \\
\text { recordings }\end{array}$ & $\begin{array}{l}\text { 1)Mindfulness, body } \\
\text { awareness training and } \\
\text { relaxation } \\
\text { 2) Usual care }\end{array}$ & 3 (time NR) sessions & NR \\
\hline Jensen, 2011 & $\begin{array}{l}\text { Live + self-hypnosis using audio } \\
\text { recordings }\end{array}$ & $\begin{array}{l}\text { 1)Cognitive restructuring } \\
\text { 2) Education }\end{array}$ & 4 (time NR) sessions & NR \\
\hline Jensen, $2009 b$ & $\begin{array}{l}\text { Live + self-hypnosis using audio } \\
\text { recordings }\end{array}$ & EMG biofeedback & 10 (time NR) sessions & NR \\
\hline Liossi, 2006 & Live + self-hypnosis + EMLA & $\begin{array}{l}\text { 1)EMLA + attention } \\
\text { 2) EMLA only }\end{array}$ & 3 (time NR) sessions & NR \\
\hline Lang, 2006 & $\begin{array}{l}\text { Live-hypnosis before } \\
\text { procedures }\end{array}$ & $\begin{array}{l}\text { 1) Empathy } \\
\text { 2) Usual Care }\end{array}$ & 1 (time NR) session & NR \\
\hline Lang, 2000 & $\begin{array}{l}\text { Live-hypnosis before } \\
\text { Procedures }\end{array}$ & Conscious sedation & 1 (time NR) session & NR \\
\hline Lang, 1996 & $\begin{array}{l}\text { Live-hypnosis before } \\
\text { Procedures }\end{array}$ & Conscious sedation & 1 (time NR) session & NR \\
\hline Harmon, 1990 & Live + self-hypnosis Once/day & $\begin{array}{l}\text { Audio-recordings with active } \\
\text { engagement }\end{array}$ & 6 (time NR) sessions & NR \\
\hline Olness, 1987 & Live + self-hypnosis twice/day & Propranolol & 5 (time NR) sessions & NR \\
\hline
\end{tabular}




\begin{tabular}{|c|c|c|c|c|}
\hline \multicolumn{5}{|c|}{ Flynn, 2018 (Review of trials evaluating the efficacy of hypnosis for chronic headache)[33] } \\
\hline Nolan, 1995 & $\begin{array}{l}\text { Hypnosis + visual imagery + self- } \\
\text { hypnosis }\end{array}$ & $\begin{array}{l}\text { 1) Non-hypnotic imagery } \\
\text { 2) "Placebo" }\end{array}$ & NR & NR \\
\hline ter Kuile, 1994 & Live + self-hypnosis & Autogenic training & NR & NR \\
\hline Spanos, 1993 & Hypnosis + visual imagery & “Placebo" & NR & NR \\
\hline Spinhoven, 1992 & $\begin{array}{l}\text { Hypnosis + visual imagery + self- } \\
\text { hypnosis }\end{array}$ & Autogenic training & NR & NR \\
\hline Melis, 1991 & $\begin{array}{l}\text { Hypnosis + visual imagery + self- } \\
\text { hypnosis }\end{array}$ & NR & NR & NR \\
\hline Levinthal, 1987 & Direct + indirect hypnosis & Relaxation training & $N R$ & NR \\
\hline Friedman, 1984 & Hypnosis + Thermal Imagery & $\begin{array}{l}\text { 1)Biofeedback } \\
\text { 2) Relaxation }\end{array}$ & NR & NR \\
\hline De Fazzano,1980 & Self-hypnosis & “Placebo" & NR & NR \\
\hline
\end{tabular}

Provencal et al, 2018 (Review of trials evaluating the efficacy of hypnosis for pain associated with burn injury wound care)[34]

\begin{tabular}{|c|c|c|c|c|}
\hline Askay, 2007 & Adapted RIA+audio recordings & Attention control & NR & NR \\
\hline Frenay, 2001 & "Permissive suggestion" & Stress reduction strategy & NR & NR \\
\hline Wright, 2000 & Adapted RIA & Usual care & 1 (15 min) session & NR \\
\hline Patterson, 1997 & Adapted RIA & Attention Control+education & 1 (25 min) session & NR \\
\hline Everett, 1993 & Adapted RIA & $\begin{array}{l}\text { 1)Attention control } \\
\text { 2)Lorazepam + hypnosis } \\
\text { 3) Lorazepam only }\end{array}$ & 1 (25 min) session & NR \\
\hline Patterson, 1992 & Adapted RIA & $\begin{array}{l}\text { 1)No treatment } \\
\text { 2) Attention control + } \\
\text { education }\end{array}$ & 1 (25 min) session & Psychologist \\
\hline
\end{tabular}

Zech et al, 2017 (Review of trials evaluating the efficacy of hypnosis for fibromyalgia)[32]

$\begin{array}{llrl}\text { Picard, } 2013 & \text { Tailored Hypnosis } & \text { Waiting list } & \text { (60 min) sessions }\end{array}$









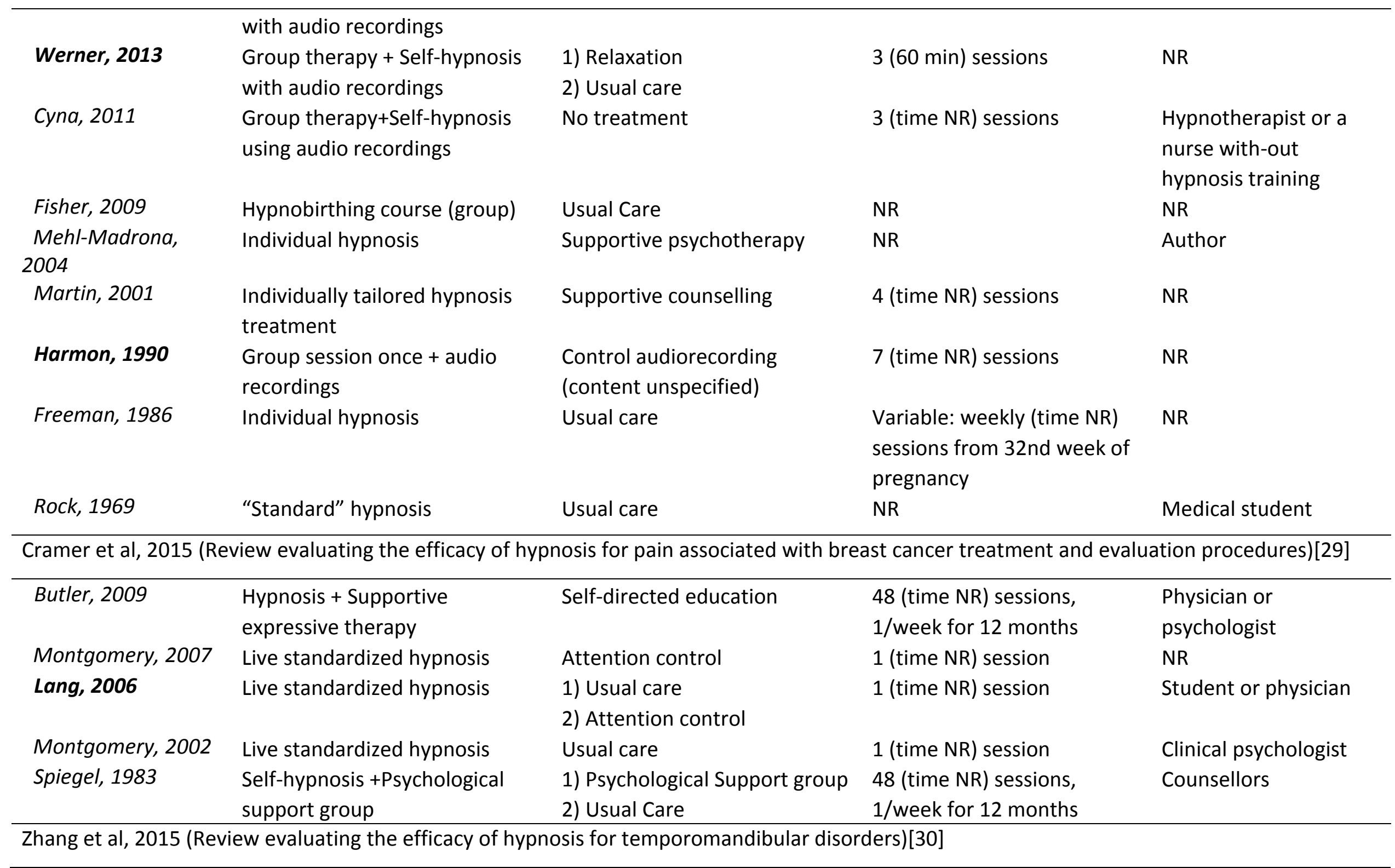




\begin{tabular}{|c|c|c|c|c|}
\hline Angelone, 2008 & Hypnosis + Deep relaxation & Attention Control & NR & Psychotherapist \\
\hline Winocus, 2002 & Hypno-relaxation & No treatment & NR & Hypno-therapist \\
\hline \multicolumn{5}{|c|}{ Adachi et al, 2014 (Review evaluating the efficacy of hypnosis for chronic pain)[16] } \\
\hline Abrahamsen, 2009 & $\begin{array}{l}\text { Hypnosis + self-hypnosis using } \\
\text { audio recordings }\end{array}$ & Relaxation and visualization & 4 (60 $\mathrm{min})$ sessions & NR \\
\hline \multirow[t]{2}{*}{ Castel, 2009} & Hypnosis + CBT + self-practice & 1) $\mathrm{CBT}$ & $12(90 \mathrm{~min})$ sessions & NR \\
\hline & $\begin{array}{l}\text { using audio recordings (in } \\
\text { group) }\end{array}$ & 2) Usual care & & \\
\hline Jensen, 2009a & $\begin{array}{l}\text { Hypnosis + self-hypnosis using } \\
\text { audio recordings }\end{array}$ & Progressive muscle relaxation & $\begin{array}{l}10 \text { (time NR) sessions, } \\
\text { frequency varied }\end{array}$ & NR \\
\hline Jensen, $2009 b$ & $\begin{array}{l}\text { Hypnosis + self-hypnosis using } \\
\text { audio recordings }\end{array}$ & Biofeedback & $\begin{array}{l}10 \text { (time NR) sessions, } \\
\text { frequency varied }\end{array}$ & NR \\
\hline Abrahamsen, 2008 & $\begin{array}{l}\text { Hypnosis + self-hypnosis using } \\
\text { audio recordings }\end{array}$ & Relaxation and visualization & 3 to 6 sessions (time NR) & NR \\
\hline Jones, 2006 & $\begin{array}{l}\text { Hypnosis + self-hypnosis using } \\
\text { audio recordings }\end{array}$ & Supportive psycho-therapy & $12(30 \mathrm{~min})$ sessions & NR \\
\hline Gay, 2002 & Jacobson's hypnosis & $\begin{array}{l}\text { 1) Progressive muscle } \\
\text { relaxation }\end{array}$ & 8 (30 min) sessions, $1 /$ week & NR \\
\hline & & 2) No treatment & & \\
\hline Palsson, 2002 & $\begin{array}{l}\text { Hypnosis + self-hypnosis using } \\
\text { audio recordings }\end{array}$ & Waiting List & 7 (45 min) sessions, 2/week & NR \\
\hline ter Kuile, 1994 & $\begin{array}{l}\text { Hypnosis + self-hypnosis using } \\
\text { audio recordings twice daily }\end{array}$ & $\begin{array}{l}\text { 1) Autogenic training } \\
\text { 2) Waiting List }\end{array}$ & 7 (60 min) sessions, $1 /$ week & NR \\
\hline Spinhoven, 1992 & $\begin{array}{l}\text { Hypnosis + self-hypnosis using } \\
\text { audio recordings twice daily }\end{array}$ & Autogenic training & 4 (45 min) sessions, 2/week & NR \\
\hline Zitman, 1992 & $\begin{array}{l}\text { Future-oriented hypnotic } \\
\text { imagery + audio Recordings ( } 49 \\
\text { hrs of self-practice) }\end{array}$ & $\begin{array}{l}\text { 1) Future oriented imagery } \\
\text { 2) Autogenic training }\end{array}$ & $\begin{array}{l}8 \text { ( } 300 \text { min total), sessions, } \\
\text { frequency NR }\end{array}$ & NR \\
\hline
\end{tabular}




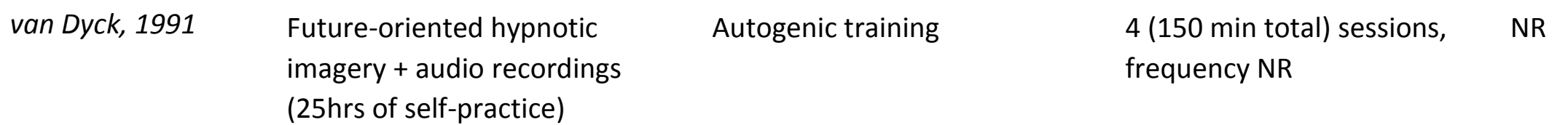

Birnie et al, 2014 (Revie of trials evaluating the efficacy for procedural pain in children and adolescents)[28] (Note: data for two studies not provided by reviewers)

\begin{tabular}{|c|c|c|c|c|}
\hline Huet, 2011 & $\begin{array}{l}\text { Three-step "Ericksonian" } \\
\text { procedure (during procedure) }\end{array}$ & Standard Care & NR & Hypno-therapist \\
\hline Liossi, 2009 & $\begin{array}{l}\text { Hypnosis using visual imagery } \\
\text { and analgesic suggestion + self- } \\
\text { hypnosis training using } \\
\text { Gardner's model + EMLA }\end{array}$ & Attention control + EMLA & NR & NR \\
\hline Liossi, 2006 & $\begin{array}{l}\text { Hypnosis using visual imagery } \\
\text { and analgesic suggestion + self- } \\
\text { hypnosis training + EMLA }\end{array}$ & Attention control + EMLA & NR & NR \\
\hline Liossi, 2003 & Analgesic or non-analgesic & $\begin{array}{l}\text { Usual care + attention } \\
\text { hypnotic suggestion before } \\
\text { control and during procedure }\end{array}$ & NR & NR \\
\hline Liossi, 1999 & $\begin{array}{l}\text { Hypnosis using visual imagery } \\
\text { and analgesic suggestion }+ \\
\text { usual care }\end{array}$ & Usual care & NR & NR \\
\hline Kuttner, 1988 & $\begin{array}{l}\text { Hypnotic suggestion using } \\
\text { child's favourite story }\end{array}$ & $\begin{array}{l}\text { 1) Distraction } \\
\text { 2) Usual care }\end{array}$ & NR & Therapist \\
\hline Katz, 1987 & $\begin{array}{l}\text { Training for self-hypnosis based } \\
\text { on active imagery tailored to } \\
\text { the child's interest (pre- } \\
\text { treatment) }\end{array}$ & Play session & NR & Psychologist \\
\hline
\end{tabular}

Cheseaux et al, 2014* (Review of trials evaluating the efficiency of hypnosis for pain associated with medical procedures)[18]

$\begin{array}{llll}\text { Slack, } 2009 & \text { Audio recorded hypnosis } & \text { Active control } & 1(20 \mathrm{~min}) \text { session }\end{array}$




\begin{tabular}{|c|c|c|c|}
\hline Montgomery, 2007 & Live hypnosis & Active control & 1 (15 min) session \\
\hline Montgomery, 2002 & Live hypnosis & Inactive control & 1 (10 min) session \\
\hline Ghoneim, 2000 & Audio recorded hypnosis & Inactive control & "Several" (time NR) sessions \\
\hline Liossi, 1999 & Live hypnosis & Active control & 2 (30 min) sessions \\
\hline Enqvist, 1997 & Audio recorded hypnosis & Inactive control & $\begin{array}{l}20 \text { min sessions, number of } \\
\text { sessions NR }\end{array}$ \\
\hline Enqvist, 1997 & Audio recorded hypnosis & Inactive control & "Several" (20 min) sessions \\
\hline Patterson, 1997 & Live hypnosis & Active control & 1 (25 min) session \\
\hline Lambert, 1996 & Live hypnosis & Active control & 1 (30 min) session \\
\hline Everett, 1993 & Live hypnosis & Active control & 1 (25 min) session \\
\hline Patterson, 1992 & Live hypnosis & Both & 1 (25 min) session \\
\hline Wall, 1989 & Live hypnosis & Active control & 2 (time NR) sessions \\
\hline Katz, 1988 & Live hypnosis & Inactive control & 2 (20 to $30 \mathrm{~min}$ ) sessions \\
\hline
\end{tabular}

Note: Trials listed with the first author and date in bold face text are trials that have been included in more than one review.

$\mathrm{NR}=$ Not reported, EMG= Electromyography; EMLA = Eutectic Mixture of Local Anaesthetics; RIA = Rapid Induction Analgesia ([37]); CBT= Cognitive Behavioural Therapy;

* Cheseaux et al, 2017- Reviewer's note: For types of hypnosis intervention used, 4 RCTs used Barber's RIA technique [37], 3 used Rhue's technique ([55]), and one each used techniques described by the authors as Ericksonian [56], Enqvist's [57], Elmal's [58], Olness and Gardner's technique [59]. 7 RCTs described hypnosis intervention in detail but they were not based on a particular model or approach. Active comparators included non-directive empathetic listening, attention support, CBT, discussion about medical procedures. For inactive comparators, 5 RCTs used no intervention. 


\section{References}

1. Carr DB, Jacox AK. Acute pain management: Operative or medical procedures and trauma clinical practice guideline. DIANE Publishing; 1997.

2. Vinall J, Grunau RE. Impact of repeated procedural pain-related stress in infants born very preterm. Pediatr Res. 2014; 75: 584-587.

3. Reddi D, Curran N. Chronic pain after surgery: pathophysiology, risk factors and prevention. Postgrad Med J. 2014; 90: 222-227. quiz 226.

4. Tsang A, Von Korff M, Lee S, Alonso J, Karam E, Angermeyer MC, et al. Common chronic pain conditions in developed and developing countries: gender and age differences and comorbidity with depression-anxiety disorders. J Pain. 2008; 9: 883-891.

5. Chou R, Hashimoto R, Friedly J, Fu R, Bougatsos C, Dana T, et al. Epidural corticosteroid injections for radiculopathy and spinal stenosis: A systematic review and meta-analysis. Ann Intern Med. 2015; 163: 373-381.

6. Vowles KE, McEntee ML, Julnes PS, Frohe T, Ney JP, van der Goes DN. Rates of opioid misuse, abuse, and addiction in chronic pain: A systematic review and data synthesis. Pain. 2015; 156: 569-576.

7. Chou R, Turner JA, Devine EB, Hansen RN, Sullivan SD, Blazina I, et al. The effectiveness and risks of long-term opioid therapy for chronic pain: A systematic review for a National Institutes of Health Pathways to Prevention Workshop. Ann Intern Med. 2015; 162: 276-286.

8. Chou R, Deyo R, Friedly J, Skelly A, Hashimoto R, Weimer M, et al. Nonpharmacologic therapies for low back pain: A systematic review for an american college of physicians clinical practice guideline. Ann Intern Med. 2017; 166: 493-505.

9. Pak SC, Micalos PS, Maria SJ, Lord B. Nonpharmacological interventions for pain management in paramedicine and the emergency setting: A review of the literature. Evid Based Complement Alternat Med. 2015; 2015: 873039.

10. Houze B, El-Khatib $\mathrm{H}$, Arbour C. Efficacy, tolerability, and safety of non-pharmacological therapies for chronic pain: an umbrella review on various CAM approaches. Prog NeuroPsychoph. 2017; 79: 192-205.

11. Elkins GR, Barabasz AF, Council JR, Spiegel D. Advancing research and practice: The revised APA Division 30 definition of hypnosis. Int J Clin Exp Hypn. 2015; 63: 1-9.

12. Barabasz A, Watkins JG. Hypnotherapeutic techniques. Routledge; 2012.

13. Yapko MD. Trancework: An introduction to the practice of clinical hypnosis. Routledge; 2012.

14. Jensen MP. Hypnosis for chronic pain management: Therapist guide. Oxford University Press; 2011.

15. Madden K, Middleton P, Cyna AM, Matthewson M, Jones L. Hypnosis for pain management during labour and childbirth. Cochrane Database Syst Rev. 2016: Cd009356.

16. Adachi T, Fujino H, Nakae A, Mashimo T, Sasaki J. A meta-analysis of hypnosis for chronic pain problems: A comparison between hypnosis, standard care, and other psychological interventions. Int J Clin Exp Hypn. 2014; 62: 1-28.

17. Eason AD, Parris BA. Clinical applications of self-hypnosis: A systematic review and metaanalysis of randomized controlled trials. Psychol Conscious. 2018. 
18. Cheseaux N, De Saint Lager AJ, Walder B. Hypnosis before diagnostic or therapeutic medical procedures: A systematic review. Intern J Clin Exp Hypn. 2014; 62: 399-424.

19. Munn Z, Peters MDJ, Stern C, Tufanaru C, McArthur A, Aromataris E. Systematic review or scoping review? Guidance for authors when choosing between a systematic or scoping review approach. BMC Med Rese Methodol. 2018; 18: 143.

20. Peters MDJ, Godfrey C, Mclnerney P, Baldini Soares C, Khalil H, Parker D. Chapter 11: Scoping Reviews. In: Joanna Briggs Institute Reviewer's Manual. The Joanna Briggs Institute; 2017.

21. Tricco AC, Lillie E, Zarin W, O'Brien KK, Colquhoun H, Levac D, et al. PRISMA extension for scoping reviews (PRISMA-SCR): Checklist and explanation. Ann Intern Med. 2018; 169: 467-473.

22. Aromataris E, Fernandez R, Godfrey CM, Holly C, Khalil H, Tungpunkom P. Summarizing systematic reviews: Methodological development, conduct and reporting of an umbrella review approach. Int J Evid-Based Hea. 2015; 13: 132-140.

23. Castañeda E, Krikorian A. Current applications of clinical hypnosis in Latin America: A systematic review of the literature. Av Psicol Latinoam. 2018; 36: 269-283.

24. Del Peral JAM, Mendoza ME, Capafons A, Basulto YL. Clinical hypnosis: Evaluation of its efficacy and quality of research in psychology. Rev Hosp Psiquiatr Habana. 2016; 13: 1-13.

25. Lee HH, Choi YY, Choi MG. The efficacy of hypnotherapy in the treatment of irritable bowel syndrome: A systematic review and meta-analysis. J Neurogastroenterol Motil. 2014; 20: 152162.

26. Khadem-Rezaiyan M, Saeidi R, Ghazanfarpour M, Mashhadi ME, Najafi MN. Relationship between hypnosis for pain management in labor and adverse neonatal outcomes: $A$ systematic review. Iran J Neonatol. 2018; 9: 70-75.

27. Nishi D, Shirakawa MN, Ota E, Hanada N, Mori R. Hypnosis for induction of labour. Cochrane Database Syst Rev. 2014: CD010852.

28. Birnie KA, Noel M, Parker JA, Chambers CT, Uman LS, Kisely SR, et al. Systematic review and meta-analysis of distraction and hypnosis for needle-related pain and distress in children and adolescents. J Pediatr Psychol. 2014; 39: 783-808.

29. Cramer H, Lauche R, Paul A, Langhorst J, Kümmel S, Dobos GJ. Hypnosis in breast cancer care: A systematic review of randomized controlled trials. Integr Cancer Ther. 2015; 14: 5-15.

30. Zhang Y, Montoya L, Ebrahim S, Busse JW, Couban R, McCabe RE, et al. Hypnosis/Relaxation therapy for temporomandibular disorders: A systematic review and meta-analysis of randomized controlled trials. J Oral Facial Pain Headache. 2015; 29: 115-125.

31. Montgomery GH, Sucala M, Baum T, Schnur JB. Hypnosis for symptom control in cancer patients at the end-of-life: A systematic review. Intern J Clin Exp Hypn. 2017; 65: 296-307.

32. Zech N, Hansen E, Bernardy K, Häuser W. Efficacy, acceptability and safety of guided imagery/hypnosis in fibromyalgia - A systematic review and meta-analysis of randomized controlled trials. Eur J Pain. 2017; 21: 217-227.

33. Flynn N. Systematic review of the effectiveness of hypnosis for the management of headache. Int J Clin Exp Hypn. 2018; 66: 343-352.

34. Provençal SC, Bond S, Rizkallah E, El-Baalbaki G. Hypnosis for burn wound care pain and anxiety: A systematic review and meta-analysis. Burns. 2018; 44: 1870-1881.

35. Noergaard MW, Håkonsen SJ, Bjerrum M, Pedersen PU. The effectiveness of hypnotic analgesia in the management of procedural pain in minimally invasive procedures: $A$ systematic review and meta-analysis. J Clin Nurs. 2019; 28: 4207-4224. 
36. Bowker E, Dorstyn D. Hypnotherapy for disability-related pain: A meta-analysis. J Health Psychol. 2016; 21: 526-539.

37. Barber J. Rapid induction analgesia: A clinical report. Am J Clin Hypn. 1977; 19: 138-147.

38. Nalamachu S. An overview of pain management: The clinical efficacy and value of treatment. Am J Manag Care. 2013; 19: s261-266.

39. Aronoff GM. What do we know about the pathophysiology of chronic pain? Implications for treatment considerations. Med Clin North Am. 2016; 100: 31-42.

40. Hoffmann TC, Glasziou PP, Boutron I, Milne R, Perera R, Moher D, et al. Better reporting of interventions: template for intervention description and replication (TIDieR) checklist and guide. BMJ. 2014; 348: g1687.

41. Richardson J, Smith JE, McCall G, Pilkington K. Hypnosis for procedure-related pain and distress in pediatric cancer patients: A systematic review of effectiveness and methodology related to hypnosis interventions. J Pain Symptom Manage. 2006; 31: 70-84.

42. Milling LS, Shores JS, Coursen EL, Menario DJ, Farris CD. Response expectancies, treatment credibility, and hypnotic suggestibility: Mediator and moderator effects in hypnotic and cognitive-behavioral pain interventions. Ann Behav Med. 2007; 33: 167-178.

43. Thompson T, Terhune DB, Oram C, Sharangparni J, Rouf R, Solmi M, et al. The effectiveness of hypnosis for pain relief: A systematic review and meta-analysis of 85 controlled experimental trials. Neurosci Biobehav Rev. 2019; 99: 298-310.

44. Jensen MP, Jamieson GA, Lutz A, Mazzoni G, McGeown WJ, Santarcangelo EL, et al. New directions in hypnosis research: Strategies for advancing the cognitive and clinical neuroscience of hypnosis. Neurosci Conscious. 2017; 3: nix004.

45. Acunzo D, Terhune D. A critical review of standardized measures of hypnotic suggestibility [Internet]. PsyArXiv; 2019. Available from: psyarxiv.com/m93uy

46 Higgins JP, Green S. Cochrane handbook for systematic reviews of interventions, vol. 4. John Wiley \& Sons; 2011.

47. Higgins JPT, Altman DG, Gøtzsche PC, Jüni P, Moher D, Oxman AD, et al. The Cochrane Collaboration's tool for assessing risk of bias in randomised trials. BMJ. 2011; 343: d5928.

48. Jadad AR, Moore RA, Carroll D, Jenkinson C, Reynolds DJM, Gavaghan DJ, et al. Assessing the quality of reports of randomized clinical trials: is blinding necessary? Control Clin Trials. 1996; 17: 1-12.

49. Verhagen AP, de Vet HC, de Bie RA, Kessels AG, Boers M, Bouter LM, et al. The Delphi list: A criteria list for quality assessment of randomized clinical trials for conducting systematic reviews developed by Delphi consensus. J Clin Epidemiol. 1998; 51: 1235-1241.

50. Friedberg JP, Lipsitz SR, Natarajan S. Challenges and recommendations for blinding in behavioral interventions illustrated using a case study of a behavioral intervention to lower blood pressure. Patient Educ Couns. 2010; 78: 5-11.

51. Goyal M, Singh S, Sibinga EM, Gould NF, Rowland-Seymour A, Sharma R, et al. Meditation programs for psychological stress and well-being: A systematic review and meta-analysis. JAMA Intern Med. 2014; 174: 357-368.

52. Davidson RJ, Kaszniak AW. Conceptual and methodological issues in research on mindfulness and meditation. Am Psychol. 2015; 70: 581.

53. Jensen MP, Patterson DR. Control conditions in hypnotic-analgesia clinical trials: Challenges and recommendations. Int J Clin Exp Hypn. 2005; 53: 170-197. 
54. Yates SL, Morley S, Eccleston C, Williams ACdC. A scale for rating the quality of psychological trials for pain. Pain. 2005; 117: 314-325.

55. Handbook of clinical hypnosis. Washington, DC, US: American Psychological Association; 1993.

56. Erickson MH, Rossi EL, Rossi SI. Hypnotic realities: The induction of clinical hypnosis and forms of indirect suggestion. New York, NY: Irvington; 1976.

57. Enqvist B, Fischer K. Preoperative hypnotic techniques reduce consumption of analgesics after surgical removal of third mandibular molars: A brief communication. Int J Clin Exp Hypn. 1997; 45: 102-108.

58. Hilgard JR, Lebraro S. Hypnosis in the treatment of pain and anxiety in children with cancer: A clinical and quantitative investigation. Los Altos, CA: Wiliam Kaufmann; 1984.

59. Olness K, Gardner GG. Hypnosis and hypnotherapy with children, 2nd ed. Philadelphia, PA: Grune and Stratton; 1988.

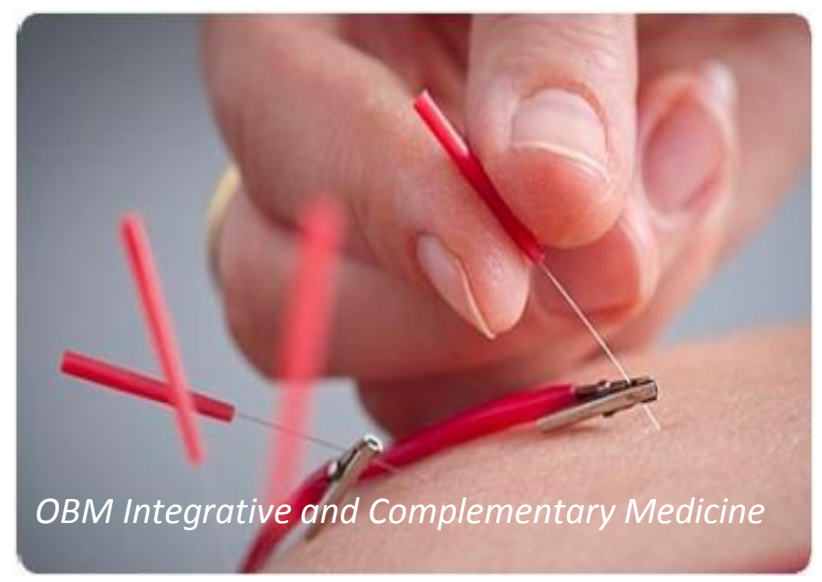

Enjoy OBM Integrative and Complementary Medicine by:

1. Submitting a manuscript

2. Joining in volunteer reviewer bank

3. Joining Editorial Board

4. Guest editing a special issue

For more details, please visit:

http://www.lidsen.com/journals/icm 